\title{
Integrating strategic and manpower planning
}

\author{
Grant Robinson \\ School of Business Leadership, University of South Africa, Pretoria
}

\begin{abstract}
The close interdependence between corporate strategy and manpower planning in the formulation and implementation of strategic plans for a healthy, viable organization is discussed. Strategy is more than products, markets and finance - the crucial role of people is gaining increasing recognition. The key aspects of strategy formulation are discussed: corporate objectives and culture, analysis of internal strengths and weaknesses, opportunities and threats in the environment, identification of potential future strategies and matching these with the company, leading to the choice of a strategy. Manpower planning elements are vital in all these steps: identification of the organization's culture and objectives, preparation of a human capability inventory, and the provision of the human resources needed to implement the strategy chosen, as well as the key areas of organizational design, reward systems, management development and leadership.
\end{abstract}

S. Afr. J. Bus. Mgmt 1980, 11: $54-61$

Die noue onderlinge afhanklikheid tussen ondernemingstrategie en mannekragbeplanning in die formulering en implementering van strategiese planne vir 'n gesonde, lewensvatbare organisasie word bespreek. Strategie is meer as produkte, markte en finansiering - die bepalende rol van mense geniet toenemende erkenning. Die sleutelaspekte van strategieformulering word bespreek: ondernemingsdoelwitte en -kultuur, ontleding van interne sterktes en swakhede, geleenthede en bedreigings in die omgewing, identifisering van potensièle toekomstige strategieë en die verenigbaarheid daarvan met die maatskappy, wat lei tot die keuse van 'n strategie. Elemente van mannekragbeplanning is krities in al hierdie stappe: identifisering van die organisasie se kultuur en doelwitte, voorbereiding van ' $n$ inventaris van menslike bekwaamhede, en die verskaffing van die menslike hulpbronne wat nodig is om die gekose strategie te implementeer, asook die sleutelareas van organisasie-ontwerp, beloningstelsels, bestuursontwikkeling en leierskap.

S.-Afr. Tydskr. Bedryfsl. 1980, 11: 54-61
The role of the corporate strategist is to provide for the ongoing health and viability of the organization. The function of the manpower planner is to provide healthy viable resources on which the strategist can draw in formulating and implementing his strategic plans. They are two sides of the same coin.

This article critically examines and pinpoints the role of the manpower planner in the strategic planning process and explodes the myth that strategic planning is all products, markets and finance. People are becoming increasingly important, and in the last resort one of the key resources available to management is simply the number and quality of the people upon whom they can draw.

The strategic planning process provides a framework for setting the corporate course. The planning process in classical form matches an environmental scan with an internal appraisal to identify trends and opportunities and to match these with the corporation's strengths and weaknesses. Put together and compared with corporate objectives, it allows the choice of a strategic plan to be made. The manpower planner has a role to play in the strategy formulation stage in identifying the core competences of the vital human resource of the particular firm, and the implications of environmental change on the quality and quantity of the human resource.

Implementing strategic plans requires skill in all fields ranging from management information systems through organization structure to reward and incentive systems. Once again the manpower planning aspects are essential to ensure the correct implementation and commitment to the chosen strategic course.

The focus of this article is to reiterate the classic steps in formulating and implementing strategy, to highlight the contributions and responsibilities of manpower planning in the genesis of a viable corporate strategy and to indicate the manpower implications of a master strategy.

\section{Master of your own destiny}

Every organization has a strategy be it explicit or implicit. The strategy is a product of evolution in the market place, and the company which sets its own strategy and attempts to be master of its own destiny and not just a passive passenger, subject to the whims of competition and market place, will consistently outperform companies which adopt the SPORT approach (Simply Press On Regardless Technique). ${ }^{1,2}$ 
The strategic problem breaks down into two dimensions, namely:

- formulating strategy, and

- implementing strategy.

The correct integration between the two dimensions is essential if the overall strategy is to succeed. People as a vital human resource are the key both to the successful formulation and particularly to the successful implementation of a chosen strategy.

\section{Formulating strategy}

The classic framework for setting strategy is given in Fig. 1 and can be summarized in six key parts: ${ }^{3}$

- setting of corporate objectives

- the analysis of internal strengths and weaknesses

- the forecasting of environmental opportunities and threats

- the identification of potential future strategies

- the matching of potential strategies to corporate values and culture

- the choice of a strategy.

\section{Corporate objectives and culture}

The setting of corporate objectives gives focus and thrust to the organization and minimizes dysfunctional activity in the organization. The objectives which emerge are obtained by interaction between the dominant coalitions in the organization and the state of the market place. Thus, for example, a family-owned business in a comfortable market niche may have as its prime objectives low risk, moderate growth and substantial dividend flows, while the subsidiary of a large aggressive marketing organization would have very different views on risk, growth and dividend policies. In essence the objective setting phase attempts to set the stamp on the corporate mission and to identify broadly what type of organization the company is to be. The qualities and preferences of the dominant coalition or individual often imprint themselves heavily on the organization. Thus ITT was Janine, Lonrho is Tiny Rowland, Anglo American is the Oppenheimer family, Anglovaal is Clive Menell and Basil Hersov, BIC is Monsieur Biche and Textron is a blend of Little, Miller and Thompson. This also explains the lack of charisma of large state-owned companies.

Organizations lacking clear objectives develop neither direction nor momentum, except possibly downwards; and as the organization gets larger, control, commitment and motivation become primary areas of concern, particularly if conflict of objectives occurs at different levels. This can, and does, lead to a waste of time and effort when different parts of the organization move in different directions simultaneously and when directives from the top of the organization are passively, or even actively, thwarted at lower levels.

The objectives, people and even premises go together to build a unique corporate culture, which implicitly, and sometimes explicitly, gives direction to the organization.

Step number one for the manpower planner must be a critical evaluation of the organization and what makes it tick. The manpower planner must be able to spell out the organization's ethos, define its long-term objectives and identify the mores of the culture within which his planning will take place. A manpower plan which does not take cognizance of the corporate culture, or the prime objectives of the dominant coalition, stands little chance of acceptance or more than token lip service. Implementation, if it goes against corporate norms, will be well nigh impossible.

\section{Strengths and Weaknesses}

The golden role in strategy, as in bridge, is to lead from strength and cover up your weaknesses. The analysis of internal strengths and weaknesses is a key activity in the formulation of a successful strategy. The competent

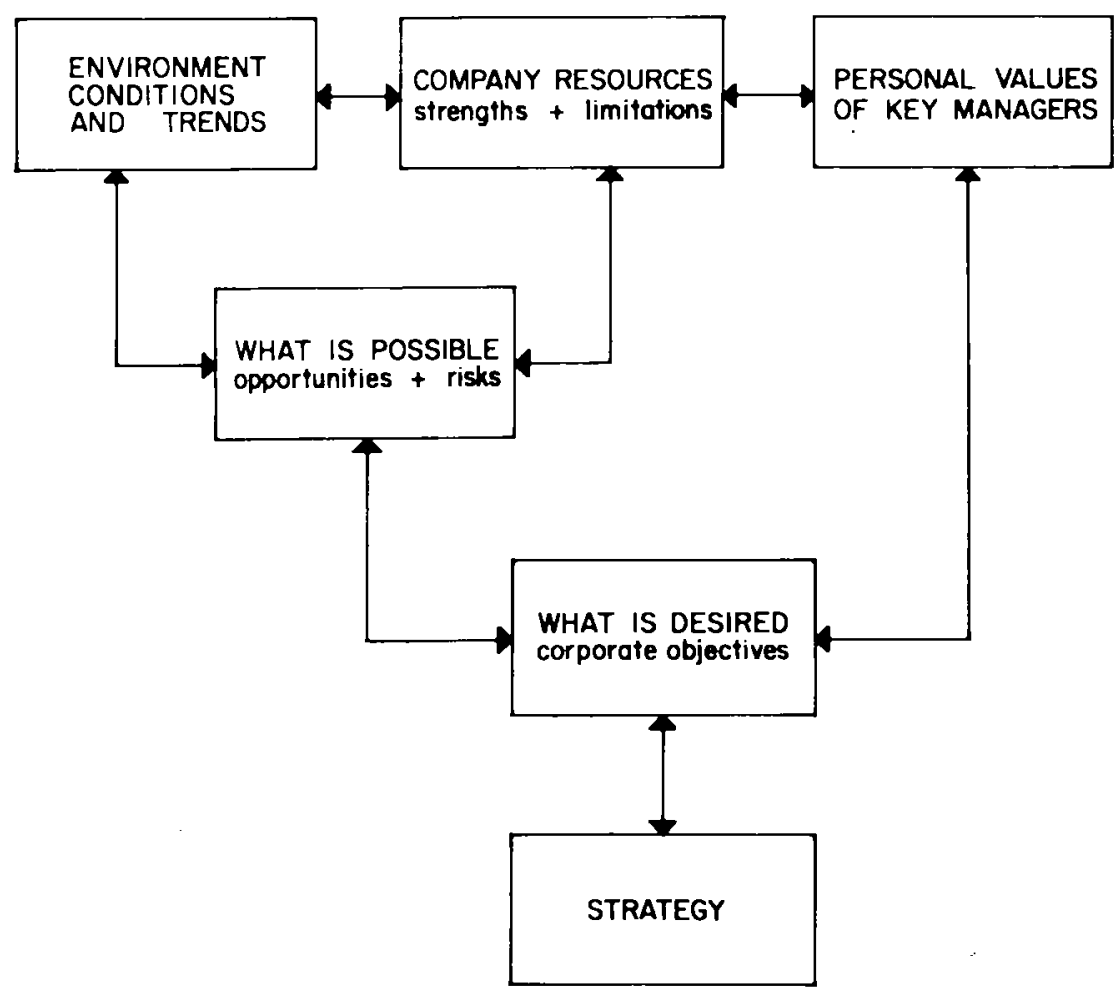


strategist develops a resource profile prior to making a strategic move. This resource profile, capability inventory or list of corporate core competences is most easily carried out by:

\section{- an analysis of functional areas}

- an analysis of management areas

- an analysis of the human side of the enterprise, and

- an analysis of the relationship between the three areas and the consistency of their fit.

Key functional areas are:

- finance and accounting

- marketing

- production, manufacturing and engineering

- research and development, and

- the human side of the enterprise.

Exhaustive check-lists exist ${ }^{4,5}$ which take each functional area and break it down into the key component parts. The health of each part is diagnosed in order to synthesize the core competences of the organization.

Thus the manpower planner must be competent to draw up a resource profile or capability inventory of the organization. His function must be correctly to assess the corporate culture, to identify strengths and weaknesses, and to critically see how the above fit into the overall strategic plan.

Check-lists for assessing the corporate capability, as far as manpower goes, and a swift look at corporate culture, are given later.

\section{Scanning the Environment}

Environmental scanning seeks to identify the emergence of major environmental trends with the firm conviction that the successful company does not just react but forecasts and adapts in advance of change. Major environmental change, if not taken into account and provided for, can turn a successful company into a corporate dinosaur.

The environmental scanning process breaks down into four key areas of technology, economics, political change and social change.

Each key area may have a major impact. Technological change such as the advent of the digital watch or the replacement of railroad transport by trucking lines are examples of major change. The railroads and the Swiss watch manufacturers will never be the same again.

Economic change is both short-term and cyclical, of duration one to three years, but also long-term and structural. The strategic function is to allow for a comfortable ride over the short-term disturbances and to choose the correct products and markets for the long-term structural change. The building industry with its low barriers to entry and low cost of exit provides a prime example of the difficulty in taking long run strategic decisions against an often uncomfortably turbulent short run environment. It's either boom or bust. Short-term financing is used to shore up medium-term cash flow problems often with disastrous results. Key skills, which may take years to acquire, run short in boom times while skilled workers quit the industry in lean years never to return again. When coupled with repressive labour legislation the situation is exacerbated.

Long run strategic change often becomes difficult to predict and impossible for the individual corporation to influence as is illustrated by the oil crises past, present, and future. Companies in energy alternatives, mainly coal and possibly uranium, are well placed for the next two decades while those still hitched to petroleum face a stormy future. The four horsemen of the economic apocalypse, namely, soaring oil prices, inflation, uncontrolled money supplies and uncontrolled debt instruments such as Eurodollars, make the economic scanning process a tough one particularly for multinationals or companies with high international exposures.

Political change may be long run and inexorably predictable as in the South African context or sharp and relatively frequent as in the United Kingdom context. Often the corporation is powerless to affect major shifts in political stance, unless it be a CIA aided multinational, and even then the results are not easily predictable. The pace of change is not that great in many instances because, while governments may go, government agencies and statutes take time and effort to dismantle. The real danger in the corporate planning sense is that the direction and pace of change is often unperceived until a wide planning gap has opened in the political dimension. The implication for the manpower planner is the need for an acute awareness of what political change can do to the structure of the human resources and the need to plan astutely over relatively long time horizons without being sidetracked by the daily noise and flak.

Social change affects consumer habits and can have quite dramatic impact as exemplified by the moves toward frozen foods, cluster housing, single bars and working women.

Once again the role of the corporate planner is to take advantage of the opportunities while guarding against risks. The role of the manpower planner is to be able to assess the effect of environmental change on the human resources available to, or required by, the organization.

\section{The choice of a strategy}

Finally, the corporate strategist matches the corporate strengths with the environmental opportunities and threats to see what is feasible, or, simply put, what God and the competition will allow. What is possible is compared with what is desirable. One man's passion may be another man's poison. The result is a strategy which is internally consistent and fits the organization well.

During each step the manpower planning elements are vital.

\section{Identify your objectives and your culture}

Can you spell out your organization's mission and objectives clearly and concisely? If it can't be done on the back of a cigarette box, someone is confused or overly complicated. This could mean a lack of corporate purpose, in which case it is extremely difficult trying to plan for people in an organization which doesn't know where it is going; or it could mean that the planner doesn't really understand in which direction the company is pointed. Either alternative is unsatisfactory. 
The way out may be either to dig by probing questions to find out from management the course they have set, or to educate the planner in the realities of the corporate course if he doesn't understand it. There is little point in starting with any of the other activities prescribed here if the planner does not know the master chart of the corporate destiny.

Is the organization's culture identifiable? A company which exists by free-wheeling opportunism cannot have its human resources identified and catered for in the same way as a large state bureaucracy. The corporate culture also identifies the type of person who is willing to work for an organization. A manager from Slater Walker would be terribly uncomfortable in the hallowed halls of Hill Samuel's marble and rosewood culture. You can neither develop nor place people easily when vast cultural chasms yawn, especially in the case of unhappy, or uneasy, corporate marriages. Ciba Geigy still is Ciba and Geigy and it will take time to get everyone into a single corporate cultural mould. A merger of Lonrho and Conzinc Rio Tinto mining interests would generate a lot of fun.

Corporate cultures can be broken down into four groups ${ }^{6}$ namely:

- the old school tie

- the Greek temple

- the net

- the existentialist

Although this is a tongue-in-cheek classification, it has much merit. With the old school tie, similar mores and reactions are common to all levels of management and action and communication is swift with even junior members knowing intuitively the mores and desires of top management. Written communication is not voluminous and the organization takes its purpose from a common ethos. The Greek temple on the other hand has functional pillars, production, marketing and so on, with a pediment of management superimposed. Each pillar stands alone and communications move up, across and then down the next pillar. Such organizations frequently have functions at loggerheads.

Corporate change in an old school tie corporation is by informal agencies, and the whole organism evolves. Greek temples need to be torn down and rebuilt - a painful process. You can't use formal manpower planning techniques on an old school tie, whereas Greek temples need improved versions of the approach which advocates that a manager spend some time in each pillar 'learning the business' before gravitating upward.

Nets are matrix organizations with functional responsibilities in one direction and project responsibilities in the other, while Existentialist organizations are similar to nets but have larger numbers of prima donnas. Research organizations and complex high technology companies tend to be net cultures while universities and ballet companies exemplify the existentialist, which has peer groups outside the organization in the form of professional societies.

Corporate manpower planning in nets requires the development of people with strong functional skills who are able to work with dual communications and loyalties without developing schizophrenia. Planning in existential cultures can be difficult as it concerns the development of 'artistes' whose frame of reference for success lies outside rather than inside the organization. Often, however, the external peer groups do the training and development and the planning process becomes one of recruitment and selection.

The corporate manpower planner must be aware of the ethos and culture of the organization and adapt his techniques accordingly. Approaches which work in one type of company may fail in a totally different environment. The cost and complexity of the planning system must also match the culture concerned.

\section{Prepare a human capability inventory}

A problem facing manpower is the twin-edged sword of inadequately forecasting the need for skilled personnel or over-forecasting and over-training skilled personnel. Each has its dangers which may be minimized by taking an inventory of the human resources and capabilities of the organization which dovetails with the environmental analysis. The correct forecasting of human talents required in the future depends both on the resource profile and the analysis of the existing capabilities, of the company.

Because the human element permeates all other segments and divisions within an organization, it must be considered. The planner must decide whether the human element is actually a resource and strength for the organization or whether there are weaknesses that may nullify efforts of management to employ other resources successfully. It should go without saying that the human resources analysis of an organization may begin with, but must go far beyond, a look at the personnel or industrial relations department! Some 'key questions' can guide the analyst in his evaluation of the human resources. A human resources checklist devised by McCarthy, Minichiello and Curran ${ }^{7}$ is given as Table 1.

The subject of organizational behaviour and human relations so permeates the nature of a company or any other type of organization that the resource appraisal must be considered a major element of the internal analysis. Many areas need to be considered and many questions should be asked. If an organization can be judged 'healthy', however, management will have done much of its job and the crucial human resources of the firm are probably a major asset to the organization. At a minimum level of 'health', the employees are satisfied generally and do not resist the organization in attempts to achieve its objectives. At a higher state of 'health', individuals subscribe to organizational goals and actively work toward the achievement of these goals, while simultaneously achieving personal goals. The human side of the enterprise does not exist in vacuo. It is vital at all echelons in the organization. Trouble at any level can well disrupt other levels and quickly turn the human resources into liabilities rather than assets. If this occurs, it is unlikely that financial or physical resources will remain strong. They are too closely interrelated to, and depehdent upon, success in the area of human resources. The human resources profile which emerges gives an idea of the organization's strategic response time and provides a basis for manpower assumptions affecting the formula- 


\section{Table 1 A human resources profile}

Use this checklist of key questions, posed by McCarthy ${ }^{7}$, when appraising the human resources in an organization.

- Is attention devoted to the human side of the enterprise in formal departments (like personnel and industrial relations) and, more importantly, in the overall managerial philosophies of the organization?

- Are there clear and equitable policies covering people associated with the oranization?

- Is there effective communication, action, and results in the areas of hiring, training, and replacement of individuals within the firm?

- Is the firm 'competitive' with others in its policies of wages, promotion, education, benefits, and the like?

- How are policies communicated throughout the organization?

- If unionized, how does the company deal with the unions and have relations been at least adequate and perhaps even beneficial?

- In all areas, does the organization have adequate and well-qualified personnel backed up by others being trained for further responsibility?

- Are there 'holes' in the organization at any level and, if so, how crucial are the spots at which these 'holes' exist?

- Is there a morale problem at any or all levels, and how does the problem manifest itself? Does management strive to achieve harmony within the organization?

- Has management given a purpose for commitment to members of the organization, and has it been accepted?

- What is the prevailing 'climate' of the organization? Does it indicate health and vitality, or a malaise which is counter-productive to organizational and even individual goals?

- What is the overall relationship between individuals and the organization? Is there a balance and do individuals appear to fulfil personal and/or organizational goals?

- Is management viewed with suspicion, or with a spirit of admiration leading to corporate effort by organizational members?

- Is there a policy of 'management by objectives' and, if so, is it actually implemented or only a slogan?

- Is an 'informal' organization apparent and, if so, does it support or counter support or counter efforts of the formal groups?

- Is management sensitive to the entire spectrum of human behaviour in the organization and has it shown wisdom in dealing with these aspects of organizational life? Or has management relied upon a mechanistic view of the organization with an ultimate neglect of important human considerations? tion of corporate strategy. However, policy formulation must find its fruition in implementation and it is necessary to ask at the formulation stage just what is the organization's ability to implement any chosen strategy. A corporate capability profile must be prepared and matched with the resources profile to determine what is possible. ${ }^{5}$ Guidelines for the capability profile are given in Table 2.

In conducting the corporate capability profile, it is necessary to analyse key tasks and, in particular, to detail what the pivotal tasks are that spell the difference between profit and loss. Each key product and market must be considered to determine what the firm does in design, production and marketing, which allows it to bring the right product or service to the right market, at the right time and at the right price. If these are likely to change, the nature of the changes must be identified.

The individuals or work groups who carry out the key tasks must be identified. If example can be found of a key task which is carried out well by one individual and poorly by another, it is necessary to identify both, and to seek to pinpoint the reasons for the differences in the next phase of the analysis.

The knowledge, skills and attitudes required to carry out the tasks need to be identified. Knowledge is often used to describe both awareness and understanding of information, facts and theories, and skill in applying these cognitive bits to real world situations. The kinds of skills required to carry out key tasks are used to identify the most capable individuals, and the kinds of skills or abilities needed to apply the more theoretical forms of knowledge considered to real world situations. Individuals who carry out the key tasks quite often share certain common attitudes or perspectives about their work or the company. These attitudes must be identified. Motivators and reasons for anger or frustration must be ferreted out.

The Capability Inventory must be conducted using a multi-level approach which is well coordinated and which defines the roles both of the personnel department and of outsiders. It will require work done at virtually all levels of the company to answer the several types of questions raised by such an inventory. It is essential to get both the broad views held by top management and the identification of more specific capabilities which must be carried out by key line and staff managers at all levels of the company.

If the company has a director of long-range planning or some individual responsible for coordinating future planning or diversification, he or she may be the ideal person to oversee this activity. Such people should design the forms used and see to their consolidation and summary. In addition, they may profitably undertake an independent inventory of their own, hopefully reflecting the objective and relatively broad perspective they should have.

The role of the personnel department should be defined

Particularly in companies which conduct formal appraisal programmes, the personnel department should be a source of key data and should be deeply involved in this activity. Care must be taken, however, to get from per- 


\section{Table 2 Corporate capability profile. Kirby} Warren $^{5}$

- Analyse Key Tasks

- what are the pivotal tasks?

- how will changes in strategy affect the tasks?

- Pinpoint Who Performs the Key Tasks

- Analyse Key People

- what knowledge is required?

- what skills are required?

- what attitudes and temperaments are required?

- Conduct the Capability Inventory

- use a multilevel approach

- coordinate

- define the role of the personnel department

- define the roles of outsiders

- Use the Capability Profile

- to define other types of work requiring similar attributes

- to combine with the non-human resource considerations

- to combine capability with market potential

sonnel answers to the kinds of questions raised above and not just answers to questions on which they have data available. Quite often, as in the accounting area, data which must be collected to meet recurring operating needs may need revision and change in focus to highlight the factors vital to specific surveys such as this. Typically, the personnel department has the kind of data needed or is in an ideal position in terms of its activities, talents and temperaments to collect and analyse them.

In some cases, it may be desirable to utilize the services of management consultants, and perhaps even industrial psychologists, to add further objectivity and expertise in analysing the types of knowledge, skills and temperaments found within the company.

The Capability Inventory is used to identify the areas of synergy between the work done and work which could be done, to combine these capability considerations with non-human resource and market potential consideration. An attempt should be made to identify other types of work which require similar knowledge skills and attitudes. The idea is to identify work which requires people who possess combinations of knowledge, skills and attitudes which characterize the key people. Just as care should be taken to analyse whether changes in technology are likely to alter the kinds of capabilities the company may require for continual success in its present business, the analysis of other types of work which might utilize these capabilities must also be future-oriented.

It is necessary to combine capability considerations with non-human resource considerations. Not to be overlooked is the degree to which new ventures will utilize existing facilities, funds or such intangibles as market image. Little attention has been given to these considerations here, not because they are unimportant, but rather because they are seldom overlooked in defining the present nature of the business or identifying opportunities for diversification. In fact, their more tangible nature often leads to their overshadowing human considera- tions. The capability inventory when considered in conjunction with these factors measures feasibility in terms of matching human and other resources.

The capability considerations should be concerned with market potential. A thorough analysis of those types of work which require capabilities similar to those that a firm's key people possess should assist in uncovering opportunities for growth and diversification which can be most easily integrated with the existing business. Two questions must be answered. First, does the work which will utilize these capabilities represent key elements in the success of the other business? Second, do these other businesses offer sufficient growth and profit potential to justify the investment of capital and human resources?

\section{Forecasting key environmental trends}

Environmental change and the ability of the organization to forecast and adapt to change dictate whether the organization will become a viable successful unit or be confined to pre-history along with other corporate dinosaurs. As pointed out earlier, the environmental scanning and forecasting process covers,

- technological change,

- economic change,

- social change, and

- political change.

The function of the manpower planner as an input to the corporate plan must be to identify the human resource impact on the firm of each key factor of on-going change.

Technology is always changing, particularly obviously where organizations are in the computer or solid state physics types of industries. The pace of change in such industries is awe inspiring. While the function of the strategic planner is to plan for technological change as it affects the corporation's products and markets, the role of the manpower planner is that, given a major technological thrust, people with skills must be available when required to implement the technology. There is no point in forecasting the change from hand crafted to quartz digital technology for a Swiss watch manufacturer and then expecting skilled hand craftsmen to suddenly master space age technology.

Economic change, as has been pointed out, has both long-term and short-term cyclical effects. The strategic role of the manpower planner is to ensure long-term health for the organization while still ensuring that shortterm cyclic fluctuations do not cause the organization and its employees to suffer unduly. As pointed out, the building industry is a perfect example of cyclic feast followed by cyclic famine as the vagaries of the business cycle play havoc with training schemes, salaries and levels of employment. Surely the manpower planning response can be more than 'Hang on, here we go again!'.

Social and political change are only too well understood by 'people people'. They are major forces which change the structures of economies and the life styles of nations. In underdeveloped and developing economies the effects of social and political change are possibly greater than in mature western economies. The Shah of Iran's unfortunate attempt to change a ninth 


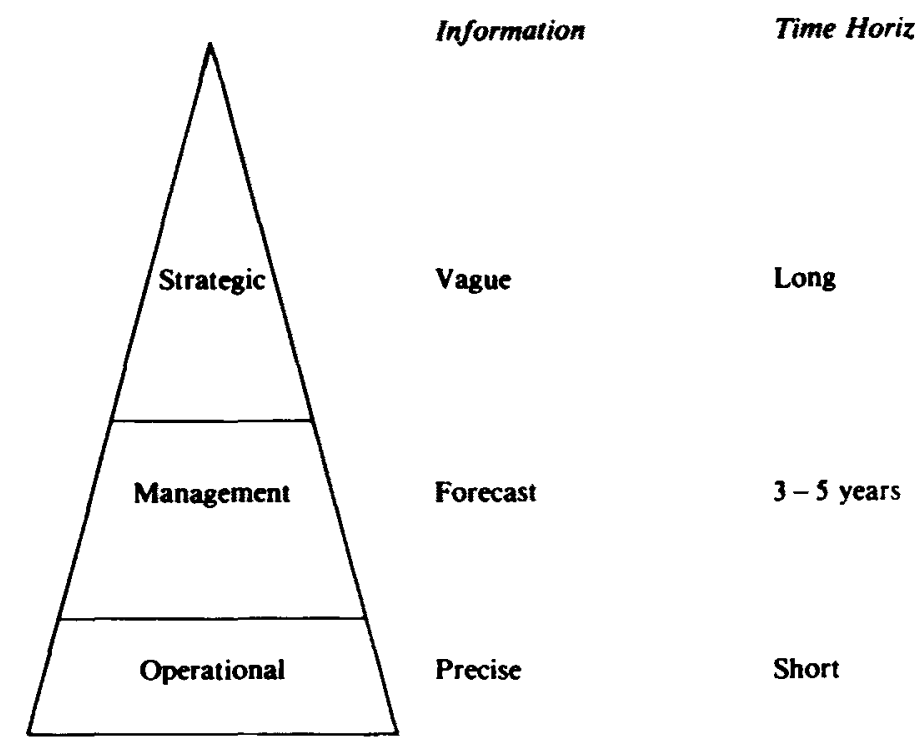

Fig. 2 The three levels of planning

century peasant and nomad population into a 20th century modern nation was doomed to failure from the start in that, as a national manpower planner, he incorrectly assumed that he could remove children from the looms, neglect the artisan class and send everyone to school. The result was a shortage of qualified artisans and an excess of highly trained people with high expectations.

The parallel problem for planners in African economies is how to plan within a framework which is realistic enough to take into account the evolving needs of the market place (in the South African case also in the light of the Wiehahn and Riekert Commissions' reports), and at the same time to be aware of the ingrained resistance to change. It's a question of 'full steam ahead - but not too fast!'.

\section{Match possibility and desire}

The synthesis of the corporate strategic plan reaches fruition when the planner considers the environmental forecast and matches it with the corporate resource profile to decide on what is possible. Relating the possible to the corporate culture limits the possibilities to a few potentially acceptable alternatives from which a strategy, or series of contingent strategies, is chosen. The end product is the corporate strategic plan.

The function of the manpower planner is to appraise the company's human resources and their strengths and weaknesses to match them with forecast environmental trends to obtain a set of feasible manpower strategies. The strategic choice is tempered in the light of the capability profile of corporate manpower, and of the other functions. Comparing the feasible alternatives with corporate objectives and culture then circumscribes what should occur. The end product is a set of broad policy guidelines within which corporate planning must occur. These form the broad outlines within which a manpower demand forecast has to be prepared as an input to the manpower planning process.

The process of strategic manpower planning as outlined above tends to be philosophical and is often not very quantitative. This is inherent in the nature of the strategic planning process which is really broad-based policy setting.
Having ascertained where the corporation is going in broad terms it becomes important to quantify these assumptions into viable planning inputs which become meaningful and workable at the operational levels in the organization.

\section{Implementation: Three levels of planning}

A useful guide to implementation is afforded by the simplicity of Fig. 2 which simply depicts the corporate pyramid with its three layers of management, namely,

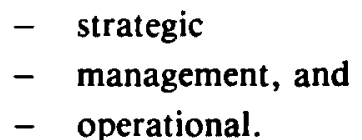

The strategic level plans in broad terms with imperfect information based on conjecture and philosophy, and tends to have a long-term orientation. The strategic lead time in an industry can vary from the launch of a new model car, three years or so, to the changing of the products of a timber grower, 15 years or more. This is the planning horizon at the strategic level.

The management level concerns itself with getting the strategic plan translated into workable plans with a horizon of three to five years. The most common planning approach is to forecast what would occur if everything kept on going as it is, and to compare this with the desired trajectory resulting from the strategic plan. The resulting gap, called the planning gap, must be bridged by the management planning process which details activities, the responsibility for each activity and the targeted result. ${ }^{8}$

Operating plans are the detailed amplification, usually in budgets and procedures, of the management plan. They provide the detailed operating guidelines for the organization and include standards against which performance could be measured.

As the purpose of this article is only to look at the strategic level a detailed description of the role of the manpower planner at the management and operating levels is not covered. This does not imply that the levels are unimportant. The planning inputs into the management level result from the strategic approach advocated 
here. The strategic plan becomes the blueprint within which the manpower plan strives to give a quantified step by step assessment of how to maximize the medium term health and viability of the enterprise. The manpower plan details the numbers, skills, training, money and all other details that quantify the impact of the strategic plan. Reporting is by comparison with forecast and the management plan is rolled over on a quarterly, halfyearly or yearly basis, depending on the enterprise. It is continually modified to provide an optimum moving target for the corporation.

The operating budgets flow from the yearly management plan and detail standards, procedures and costs. Variance reporting against budget is used and once set the targets are seldom changed until the next budgeting period.

Implementation of the strategy at the strategic planning level requires that key areas need to be covered in organizational design, information systems, management control system, reward system, staffing and management development, leadership, and corporate culture.

Each of these areas needs to be correctly weighed and balanced against the corporate plan. A series of checklists can be developed to assess the impact on the management planning process. The other areas, such as information systems, are not covered here.

\section{Organizational Design}

- Select the basic structure best suited for executing the chosen strategy.

- Identify key tasks to be performed and kinds of decisions required.

- Assign responsibility for the foregoing, together with appropriate allocation of authority.

- Provide for coordination of activities thus separated and arrange for an hierarchy of supervision, systems of committees, the needed project teams, task forces, etc.

\section{Reward Systems}

- Adopt a comprehensive plan for compensation, consistent with corporate strategy and needs of personnel. Consider the base salary, incentive compensation and equity participation schemes and their impact on performance.

- Provide specialized forms of recognition designed to reward unusual accomplishments and to fit individual needs.

- Incorporate system of constraints and penalties, as needed to constrain dysfunctional behaviour.

\section{Staffing and Management Development}

- Establish a selective system of executive recruiting based on the needs of corporate strategy, the philosophy of management, and the organizational climate.

- Assign individuals to essential tasks in accordance with the knowledge and skills they possess or can develop. Adjust the assignments to the nature of available skills, where necessary.

- Provide for the continuing development of requisite technical and managerial skills by means of a soundly conceived and effectively administered programme of on the job training and formal instruction and study.

\section{Leadership}

- Provide the leadership necessary for the successful formulation and implementation of strategy, integrating the roles of architect of strategy, organization leader, and personal leader into a harmonious unity.

- Lead in building and maintaining an organizational climate conducive to successful accomplishment of strategic purposes. Obtain commitment to the chosen strategy, and motivation for its accomplishment, encourage cooperation and development of individual competences.

\section{Integrating strategic and manpower plans}

Manpower planning cannot be done in a void. Pity the poor manpower planner who is confronted with a fait accompli of massive corporate change at the strategic level when he should have been party to its formulation.

The manpower planning aspects of the strategic process are more in need of understanding than the marketing and finance aspects. A competent strategic plan will have as its output a blueprint of corporate objectives and strategy which carefully considers environmental change, matches it to the organization's core competences and results in the broad outline of a manpower demand forecast. This forecast needs to be amplified and made meaningful at the management planning level to allow for the specifics of a gap analysis as it affects the manpower plan and a series of budgets and standards.

Success is achieved by integrating and balancing reality with what is the ultimate desire and the provision of leadership, human resources and a culture and systems to provide a workable whole.

\section{References}

1 STEINER, GEORGE A. 'The Critical Role of Management in Long Range Planning', Arizona Review, April 1966.

2 WEINER, JACK B. 'What Makes a Growth Company', Duns Review and Modern Industry, November 1974.

3 CAPLAN, ROBERT H. 'Corporate Strategy: Design and Implementation', In: McCarthy, D.J., Minichiello, R.J., \& Curran, J.R., Business Policy and Strategy, Irwin, p. 97, 1975.

4 BUCHELE, ROBERT B. 'How to Evaluate a Firm', Calif. Mgmnt Rev. Fall 1962.

5 KIRBY WARREN, E. The Capability Inventory: Its Role in Long Range Planning, Mgmt. of Person. Q, 3, no. 4, 1965.

6 HANDY, CHARLES, The Gods of Management, Pan, 1979.

7 MCCARTHY, D.J., MINICHIELLO, R.J. \& CURRAN, J.R., Business Policy and Strategy, Irwin, pp. 106-131, 1975.

8 ARGENTI, JOHN, Corporate Planning, George Allen \& Unwin, 1968, pp. $70-166$. 